\title{
ENCUESTAS DE OPINIÓN Y DECISIÓN POLÍTICA
}

\author{
Juan Díez Nicolás
}

Universidad Complutense de Madrid

Desde que Lippman escribiese su obra pionera sobre la opinión pública como uno de los ingredientes indispensables del sistema democrático de gobierno, todos los gobiernos, más o menos democráticos, incluso claramente no democráticos, han pretendido estar gobernando de acuerdo con «la opinión pública». Ningún político se atrevería hoy a afirmar que sus actuaciones o planes de gobierno van en sentido contrario a la opinión pública, sino que todos buscan la legitimidad de estar de acuerdo con ella, o al menos con la de la mayoría. Se trata, pues, de una cuestión no controvertida, no contestada, sino unánimemente aceptada, de manera que desde los sistemas más totalitarios a los más genuinamente democráticos, sus voceros pretenderán estar gobernando de acuerdo con «la opinión pública», cualificada o no como mayoritaria.

El debate se ha desplazado, sin embargo, a la cuestión de quién habla en nombre de la opinión pública, y en este caso sí que se observan amplias y profundas discrepancias. ¿Quién representa a la opinión pública?, ¿quién está legitimado para interpretarla?, ¿quién puede hablar en su nombre? Naturalmente, y por lo que antes se ha indicado, todos los gobiernos pretenden representar y hablar en nombre de la opinión pública. Pero todas las oposiciones, más o menos legales, más o menos mayoritarias, pretenden igualmente representar y hablar en nombre de ella. En las democracias reales, en las que hay elecciones libres, la cuestión se resuelve fácilmente, pues habla en nombre de la opinión 
pública (mayoritaria en este caso, pues en las democracias reales no suele haber lugar para las unanimidades) el partido o partidos que hayan recibido suficiente respaldo electoral en las últimas elecciones como para formar gobierno. En los sistemas no democráticos, evidentemente, tanto el gobierno de turno como la oposición reclamarán representar a la opinión pública mayoritaria, pero esa reclamación no podrá ser verificada empíricamente, por lo que siempre constituirá una mera suposición indemostrable.

En las democracias reales, por otra parte, el gobierno ha sido elegido por la mayoría de los ciudadanos, pero sólo de manera global puede pretender hablar en nombre de la opinión pública mayoritaria, puesto que el número de cuestiones sobre las que los ciudadanos pueden tener opinión es tan enorme que resultaría imposible que cada una de ellas contase con el mismo respaldo mayoritario de la opinión pública. De hecho, cualquier gobierno, aunque haya sido respaldado electoralmente por una mayoría absoluta de los ciudadanos, adoptará decisiones y tratará de llevar a cabo políticas para las que no cuenta con el respaldo de una mayoría de electores.

Pero, como se ha dicho, el debate se produce porque distintos intermediarios pretenden representar a la opinión pública cada vez que hay una cuestión de debate público, es decir, una cuestión que interesa a la opinión pública y sobre la que ésta tiene opinión. Es importante aclarar aquí que no todas las cuestiones, por importantes que sean, son cuestiones que interesen a la opinión pública y sobre las que ésta tenga una determinada posición. Es evidente que la mayoría de los ciudadanos carecen de opinión sobre si el arancel que se paga por la importación de determinados productos industriales debería incrementarse o no en un cinco por ciento, o sobre cuál debería ser la proporción de arena admisible en la fabricación del aglomerado que se utiliza en la construcción de autopistas. De hecho, hace años, la subida de una simple peseta en el precio del litro de gasolina podía desencadenar grandes debates públicos e incluso huelgas y manifestaciones de protesta, pero en estos últimos años las continuas fluctuaciones en el precio de los carburantes, que suben con mucha más facilidad e intensidad que bajan (cuando bajan), apenas reciben la más mínima atención por parte de la opinión pública.

Como tuve ocasión de escribir hace bastante tiempo, para que exista opinión pública sobre un objeto social (una política, un líder, una idea, una institución) es requisito indispensable que exista conocimiento de ese objeto social, es decir, que el público (los ciudadanos) tengan información sobre ese objeto social. Pero, a partir de ese momento, el público puede reflexionar sobre esa información y, finalmente, adoptar una actitud hacia ese objeto social, o puede aceptar la actitud que le venga incluida conjuntamente con la información desde una fuente de información determinada. Parece haber coincidencia en afirmar que en una sociedad democrática los ciudadanos deberían ser capaces de recibir las distintas informaciones (a veces con evaluaciones incluidas) sobre diferentes objetos sociales, reflexionar sobre esas diferentes informaciones y evaluaciones y, finalmente, producir su propia actitud evaluadora. Ése sería el 
desiderátum. Lo importante en ese proceso, debe subrayarse, es que en los sistemas democráticos hay diferentes fuentes de información que tratarán de transmitir sus propias evaluaciones sobre muy diferentes objetos sociales a los ciudadanos, pero éstos podrán compararlas, evaluarlas, reflexionar sobre ellas y, finalmente, adoptar su propia actitud, juicio o evaluación. En los sistemas no democráticos, por el contrario, existe un gran desequilibrio entre las fuentes de información, de manera que el gobierno siempre tiene muchas más posibilidades de «formar» la opinión pública que las otras fuentes emisoras de información, generalmente clandestinas. Pero la experiencia demuestra que, incluso en los sistemas totalitarios, ni siquiera el poder político cuenta con la exclusiva en la transmisión de informaciones y evaluaciones o juicios. De la misma manera que, en los sistemas más democráticos, algunos grupos de poder cuentan con mayores posibilidades de transmitir informaciones y evaluaciones o juicios a los ciudadanos y, por tanto, con más posibilidades de influir sobre la opinión pública.

En consecuencia, en todos los sistemas, pero muy especialmente en los no democráticos, la opinión pública suele formarse no a través de un proceso racional y reflexivo a través del cual los ciudadanos forman su propia opinión mediante el contraste de las diversas informaciones y evaluaciones que hayan recibido, sino que suele formarse mediante la adopción de evaluaciones «prefabricadas» que los ciudadanos reciben junto con la información. Es evidente que los ciudadanos forman sus actitudes individuales a partir de los agentes de socialización, como se ha reconocido desde los pioneros de la sociología, es decir, a través de la familia, el grupo de juego infantil, la escuela, la iglesia o confesión a la que se pertenezca y, más modernamente, a través de los medios de comunicación y de los grupos sociales a los que se pertenece (o a los que se querría pertenecer, los denominados grupos de referencia). El papel de los medios de comunicación en la conformación de la opinión pública ha sido objeto de múltiples y repetidas investigaciones, y no puede ser ignorado, especialmente en los sistemas no democráticos. Pero no debe olvidarse que, en dichos sistemas, el ciudadano sabe que los medios de comunicación están sesgados y, por tanto, genera «anti-cuerpos», es decir, está alerta respecto al hecho de que no hay, o no hay la suficiente, libertad de información en los medios de comunicación. En los sistemas democráticos, sin embargo, con frecuencia se asume que todos los medios de comunicación son igualmente objetivos y fiables, por lo que los sistemas de defensa frente a los intentos de manipulación no están generalmente activados, lo que puede llevar a la opinión a adoptar juicios de valor sobre los que no ha reflexionado lo suficiente; en definitiva, a ser manipulable por los medios de información.

En cualquier caso, y sea cual sea el modo en que se forma la opinión pública, lo importante es saber quién y cómo mide los estados de opinión y, sobre todo, qué pueden hacer los diferentes actores políticos con esas mediciones, con esos conocimientos sobre la opinión pública. Respecto a la primera cuestión, debe indicarse que durante siglos todos los ocupantes del poder político 
han proclamado conocer y representar a la opinión pública y, por tanto, hablar en su nombre. Posteriormente, los periodistas defendieron su papel de intérpretes de la opinión pública mayoritaria, con gran frecuencia para, sobre esa base de legitimidad, mostrar su acuerdo o desacuerdo con los gobiernos de cada momento. Los representantes de confesiones religiosas muy diversas, los líderes de toda clase de grupos sociales (étnicos, empresariales, sindicales o de cualquier otro tipo) han reclamado igualmente ser los fieles intérpretes de aquellos en cuyo nombre dicen hablar. Y, más modernamente, los científicos sociales, a través de las encuestas, han reclamado ser capaces de conocer, de forma objetiva y científica, cuál es la opinión pública sobre los temas más diversos.

La experiencia española de estas últimas décadas puede ser ilustrativa de estos debates sobre quién habla realmente en nombre de la opinión pública y qué debe hacer el poder político con esos conocimientos sobre lo que es (o parece ser) la opinión pública. En 1963, en pleno franquismo, un ministro del gobierno que pretendía introducir cambios importantes en el sistema político para "democratizar el régimen», Fraga Iribarne, creó el Instituto de la Opinión Pública, y encargó su puesta en funcionamiento a dos (entonces jóvenes) sociólogos, González Seara y quien firma este artículo, por lo que el lector me permitirá que a partir de ahora hable a veces en primera persona. Debe recordarse, para quienes ahora son jóvenes, que en esa fecha no había en España ninguna institución, pública y menos aún privada, que llevase a cabo estudios mediante encuesta y, desde luego, no con encuestas representativas de la población basadas en muestras seleccionadas por sistemas probabilísticos. Parece que se publicaba (un resto de la antigua Secretaría de Prensa y Propaganda) un boletín denominado OPINIÓN que pretendía ofrecer resultados de encuestas, aunque nunca se especificaba dónde y cómo se hacían las entrevistas. Por otra parte, hubo algún antecedente de encuestas, pero no nacionales ni representativas de la población española, sino entre universitarios, como alguna realizada por el Seminario de Derecho Político de la Universidad de Salamanca (es decir, por el profesor Tierno Galván) y otra, cuyos resultados fueron incluso comentados en las revistas norteamericanas Time y Newsweek, realizada en la Complutense madrileña en 1956 por el profesor Pinillos.

Cuando acepté la oferta de Fraga para regresar desde la Universidad de Michigan en Ann Arbor para hacerme cargo del Departamento Técnico del IOP, y sabiendo cuáles eran las coordenadas políticas en las que tendría que trabajar, en la primera conversación que tuve con él, le presenté lo que consideraba como bases mínimas de acuerdo sobre mi compromiso, con el fin de evitar malentendidos en el futuro. Esas bases mínimas eran que yo aceptaba el hecho de que quien paga las encuestas tiene el derecho a decidir en cada caso si los resultados se publicaban o no, pero si se decidía que éstos se publicaran, yo tenía derecho a que se publicasen íntegramente tal y como se los entregáramos desde el IOP, sin ningún tipo de "retoque» y sin "censura parcial» (es decir, publicando los resultados de unas preguntas pero no los de otras, lo que impli- 
caba poder desnaturalizar el significado de los resultados que sí se publicaban). Debo decir que González Seara estaba plenamente de acuerdo con esos planteamientos, y que Fraga no sólo los aceptó, sino que los cumplió escrupulosamente durante el tiempo que fue ministro (1963-69), que fue el mismo tiempo que yo estuve en el IOP, ya que al cesar él dimití yo también, aunque pude haber continuado con su sucesor, como hicieron otros que posiblemente tenían más motivos para haber dimitido. En realidad, y ahí está el Banco de Datos del CIS, todas las encuestas que se hicieron durante esos seis años se publicaron, excepto dos: una realizada en el Campo de Gibraltar cuando se cerró la frontera con el Peñón, y que el ministro Castiella pidió que se mantuviese "secreta" porque "afectaba a la seguridad del Estado", y otra sobre unas elecciones municipales en Madrid en 1968 (que, afortunadamente, no se publicó porque, aunque se acertó plenamente el resultado, era evidente que aquella encuesta habría dado carta de naturaleza democrática a unas elecciones que no lo eran, y en las que no acertar era imposible porque, como es lógico, los «electores» sólo conocían la candidatura oficial).

La "no publicada» encuesta sobre el Campo de Gibraltar proporciona, sin embargo, una anéctoda enormemente interesante respecto a la novedad que implicaba, sobre todo para los que estaban en el poder, la realización de encuestas. Antes de iniciar las entrevistas en los domicilios a la muestra estadística seleccionada en determinados municipios de Cadiz y Málaga, tuve que pedir autorización al general-gobernador de la Zona del Campo de Gibraltar, a quien llevé una carta personal de Fraga. Después de leerla detenidamente, el general-gobernador me miró y dijo: «Este Manolo tiene unas ocurrencias, y ahora le ha dado por esto de las encuestas... Pero si el gobierno quería saber la opinión de la población de la Zona sobre el cierre de la verja... ¡no tenían más que haberme preguntado a mí!».

Es cierto que no podíamos hacer toda clase de preguntas, pero no porque el gobierno no nos hubiese dejado (cosa probable, pero no totalmente, ya que el gobierno siempre tenía la potestad de decidir no publicar una encuesta), sino porque la falta de libertad impedía que los ciudadanos contestaran lo que realmente pensaban, lo que habría sido peor puesto que se habrían publicado resultados reales que, sin embargo, no reflejaban las opiniones auténticas de los ciudadanos. Pero no es menos cierto que, con cierta habilidad por parte del equipo directivo del IOP (tácitamente aceptada por el propio Fraga, que nos dejaba hacer), se formularon y publicaron muchos resultados que, bien interpretados, proporcionaban una información de gran importancia sobre los cambios que se estaban ya produciendo en la sociedad española, y que en ocasiones llevaron a altas jerarquías de la Iglesia, de los ministerios económicos «tecnócratas» y de otros estamentos o poderes "fácticos» a pedir a Fraga las cabezas de los responsables de esas encuestas, peticiones que nunca fueron aceptadas pero de las que siempre fuimos debidamente informados. Pienso que, con la mayor objetividad que proporciona la distancia histórica respecto a aquellos momentos, siempre nos movimos en el límite, como lo atestigua el uso que unos y 
otros, partidarios y opositores al régimen, hicieron de los datos del IOP, y como lo demuestra que el IOP fuese admitido como socio en la realización de estudios internacionales comparados de la importancia del dirigido (en 1968) por alguien tan poco sospechoso de poco demócrata como Johan Galtung sobre las Imágenes del Mundo en el Año 2000.

Lo que la pequeña historia de esa época ha puesto de manifiesto, sin embargo, es que los datos del IOP fueron absolutamente cruciales para «informar" a todas las fuerzas políticas y sociales, tanto en el gobierno como en la oposición (clandestina entonces), de los cambios que se estaban operando en la sociedad española, puesto que la publicación de todos estos datos, aunque no suministraban toda la información deseable, proporcionaban mucha más de la que cabía esperar en ese régimen. Por otra parte, la creación y funcionamiento del IOP abrió el camino para que, desde el sector privado, se pidiese y obtuviese autorización para realizar estudios, primero sólo de mercado e inmediatamente de opinión, por lo que el IOP fue en sí mismo un elemento innovador, liberalizador y de apertura democrática desde un régimen autoritario. Los estudios FOESSA, y las numerosas consultoras e institutos privados de opinión que proliferaron durante los años sesenta y setenta, no hubieran sido posibles sin la existencia del IOP. Pero, además, el IOP fue el modelo que adoptaron todas estas instituciones privadas, tanto en lo que se refiere a los aspectos metodológicos (diseño de la muestra, entrevistas cara-a-cara) como incluso al modo de presentar los informes (con tablas en las que se incluían las respuestas según el sexo, la edad, etc.), aspectos que siguen utilizándose por muchos en la actualidad.

Cuando, en 1976, acepté la dirección del IOP que me ofreció el recién nombrado presidente del gobierno, Adolfo Suárez, le planteé el mismo modus operandi que a Fraga, pero con el convencimiento de que tendría las manos mucho más libres, como así fue. El IOP pudo entonces preguntar todo lo que, imitando a Woody Allen, «siempre habíamos querido preguntar pero nunca nos atrevimos a preguntar»... sobre política. Desde las encuestas realizadas para conocer las intenciones de voto en el referéndum sobre la Ley de Reforma Política de 1976 hasta las encuestas preelectorales de 1977 y 1979, el IOP, y su sucesor, el CIS, que tuve el honor de fundar en 1977, después de las primeras elecciones democráticas, llevaron a cabo encuestas sobre todos los temas más "calientes» de la transición política a la democracia, incluidas las encuestas sobre la legalización del PCE, que demostraron que más de tres cuartas partes de los electores consideraban imprescindible la legalización de todos los partidos como condición sine qua non para aceptar la legitimidad de esas primeras elecciones de la democracia.

La doble experiencia de haber llevado a cabo encuestas para el poder político en un sistema no democrático y en un sistema democrático permite obtener algunas consecuencias sobre la función de las encuestas en ambas situaciones, tanto para el poder político como para la sociedad. Las encuestas, si están bien hechas, proporcionan información sobre cuáles son las opiniones, deseos y 
expectativas de los ciudadanos sobre múltiples cuestiones, y a veces también proporcionan información sobre aquellos temas que no interesan o interesan poco a los ciudadanos, temas que no son, por tanto, de opinión pública puesto que no son conocidos por ella. A lo largo de estas páginas se ha destacado el importante papel que las encuestas del IOP tuvieron para informar al gobierno, pero también a la oposición y a los investigadores y estudiosos en general, de los estados de opinión y sus cambios en aquella década y media en que la sociedad española experimentó un intenso cambio económico y social que hizo posible el cambio político de los años siguientes. Pero no se ha insistido lo suficiente, sin embargo, en la importancia de la publicación y difusión de aquellas encuestas, y luego también las procedentes de otros institutos privados, sobre la propia clase política del régimen. En efecto, la continuada difusión de esos resultados y de los análisis más académicos basados en ellos, que sirvieron para la elaboración de tesis doctorales o para su publicación en libros y artículos en revistas profesionales, e incluso en artículos publicados en la prensa diaria, fue como una especie de "gota a gota» que fue infiltrándose poco a poco en un número creciente de miembros de la clase política gobernante, especialmente los más jóvenes, haciéndoles ver cada vez con mayor claridad que las posibilidades de supervivencia de aquel régimen estaban limitadas, en el mejor de los casos, a la vida de su fundador. Puede parecer intrascendente, pero a partir de los años sesenta una gran mayoría de los integrantes de la clase política gobernante, que además no era homogénea, estaba ya ejerciendo la política con un ojo mirando al presente y el otro mirando al futuro y, por tanto, tomando sus medidas para poder seguir teniendo un papel en el futuro. Poco a poco, el conocimiento de la realidad social que proporcionaron los sociólogos desde perspectivas ideológicas muy diferentes fue calando en la clase política gobernante y, también, en la clase política de la oposición. Unos y otros tuvieron que aceptar que la sociedad caminaba de forma imparable hacia la democracia, pero que ese camino no incluía las revoluciones que algunos deseaban, ni tampoco una vuelta al pasado que otros añoraban. Las encuestas proporcionaron, a unos y a otros, dosis de sensatez y de realismo, las que proporcionaban los datos. En cuanto a la sociedad, se acostumbró también poco a poco a conocerse mejor a sí misma, y el lenguaje sociológico fue impregnando las informaciones en los medios de comunicación y en las conversaciones cotidianas, de manera que los españoles descubrieron que las encuestas proporcionaban datos sobre cómo éramos que no siempre estaban de acuerdo con lo que desde los medios oficiales, o desde los medios oficiosos de la oposición clandestina, se decía que éramos.

No es preciso insistir en que, a partir de 1976, este proceso de auténtica «retro-alimentación» se aceleró de manera extraordinaria. Las encuestas proporcionaron una valiosa información para que el poder político (los gobiernos de Suárez) pudiera contrastar de forma inmediata los estados de opinión sobre los cambios que se preparaban, y para comprobar los efectos y reacciones de dichos cambios en la opinión pública. Pero la oposición también pudo saber 
con mucho mayor rigor en qué aspectos podían presionar al gobierno y en cuáles no recibirían el apoyo de los ciudadanos, de la "opinión pública». Toda la clase política, en el gobierno o en la oposición, llevaba en sus carteras datos sobre los estados de opinión que les proporcionaban sus asesores sociológicos cuando se sentaban en las mesas de negociación. Las encuestas, por tanto, facilitaron de manera innegable todo el proceso de la transición política, al tiempo que, al informar igualmente a los ciudadanos, ayudaban a moderar actitudes y comportamientos, así como a educarlos en los nuevos valores democráticos, permitiéndoles comprobar que ciertas actitudes eran minoritarias o poco aceptadas por la sociedad española en su conjunto.

Consolidada la democracia, las encuestas han continuado siendo una fuente constante de información para toda la clase política, tanto en el gobierno como en la oposición, y han continuado proporcionando una «retro-alimentación» para la propia sociedad. Dejando ahora aparte las encuestas electorales, que merecen un capítulo aparte, y sobre las que habitualmente se escribe más, debe señalarse que las encuestas han tenido en el pasado y tienen en el presente un papel muy relevante para llevar a cabo procesos de reforma en las administraciones públicas y en el planeamiento y la evaluación de toda clase de políticas públicas. Actualmente, apenas hay que esforzarse para convencer a un político de lo necesarias que son las encuestas en todo el proceso de toma de decisiones, de implantación de nuevas políticas, de evaluación de los efectos de esas políticas.

Se ha planteado con frecuencia, sin embargo, la polémica sobre si los gobiernos gobiernan "a golpe de encuesta». Eso se ha dicho de los gobiernos de UCD, de los del PSOE y de los del PP. No se va a entrar aquí en la polémica sobre si los gobiernos deben o no deben actuar con arreglo a lo que dicen las encuestas, entre otras razones porque la experiencia demuestra que ningún gobierno ha gobernado "a golpe de encuesta». Lo que sí parece cierto es que cualquier gobierno quiere saber qué opinan los ciudadanos sobre lo que piensan hacer, sobre lo que están haciendo y sobre lo que han hecho, y no parece que eso sea malo, sino todo lo contrario. Pero conocer no significa actuar de acuerdo con lo que la opinión pública quiere. Si ése fuese el caso, posiblemente no habría impuestos y, sin embargo, todo gobierno continúa recaudando impuestos. En otras palabras, los políticos, como los empresarios, como los sindicatos, como cualquier actor social que tiene que tomar decisiones que afectan a otros, deben tener conocimiento de los estados de opinión de los afectados por sus decisiones, pero unas veces actuarán haciendo caso a esas opiniones y en otros casos no. Lo importante es que las encuestas proporcionan información, una pieza de información importante pero no la única, que cualquier político debe tomar en consideración, junto con muchas otras informaciones, para luego tomar sus decisiones.

Estos últimos años, sin embargo, se ha podido comprobar la existencia de ciertas amenazas sobre las encuestas. En primer lugar, y debido al importante papel que éstas han tenido en la información a la sociedad, algunas encuestas 
se hacen, y sobre todo se publican, no tanto para informar a la opinión, sino para manipularla con informaciones falsas o engañosas. Esta práctica ha sido más frecuente en relación con las encuestas preelectorales, pero no de forma exclusiva, pues los políticos y los que representan a otros poderes sociales «fácticos» han aprendido a utilizar la publicación de encuestas como instrumentos de sus campañas de imagen, relaciones públicas y electorales, a veces incluso dirigidas a influir no sobre los electores, sino sobre los dirigentes de su propio partido u organización. Por otra parte, algunos medios de comunicación, y algunos profesionales de la comunicación, han aprovechado los errores o las manipulaciones de algunas encuestas para intentar recuperar el protagonismo que en otro tiempo tuvieron como intérpretes de la opinión pública. En efecto, desprestigiando el valor de las encuestas, a veces con la complicidad de algunos profesionales que las llevan a cabo, lo que se pretende es precisamente recuperar el papel que los profesionales de la comunicación o la información tuvieron como asesores de los políticos, papel que habían perdido durante la transición política a favor de sociólogos y auscultadores de la opinión pública.

Finalmente, otra cuestión sobre la que suele haber cierta polémica es la de si el gobierno debe o no tener su propio instituto para realizar los estudios de opinión. Hay, evidentemente, razones a favor y en contra de que lo tenga, pues la polémica se inició ya en 1976, antes de las primeras elecciones generales, y se ha suscitado una y otra vez hasta el momento presente. Una comparación con lo que existe fuera de España demuestra que hay países democráticos cuyos gobiernos disponen, como una oficina pública más, de algún tipo de organismo cuya función es realizar encuestas de opinión pública, así como que hay otros países igualmente democráticos que carecen de ese servicio, pero que encargan encuestas a empresas privadas. Pero, además, la mayoría de los gobiernos autónomos dispone igualmente de servicios de estudios con esa misma función. Incluso la Unión Europea realiza periódicamente, a través de los Eurobarómetros, estudios de opinión pública sobre su gestión. La experiencia ha demostrado, por otra parte, que los partidos políticos siempre se han opuesto a que el gobierno disponga de un centro para el estudio de la opinión pública... cuando están en la oposición, pero suelen defender la necesidad de su existencia cuando están en el gobierno. En realidad, esta cuestión ha dejado de tener importancia en la actualidad. Lo que importa no es si el gobierno tiene o no un centro semejante, sino si además pueden existir en el sector privado o público otros centros con capacidad para investigar y publicar libremente sus resultados sin cortapisas por parte del gobierno. Incluso la existencia del IOP en los años sesenta encontró su justificación en que, casi de forma inmediata a su puesta en marcha, se autorizó a centros similares en el sector privado a realizar trabajos de investigación de la opinión pública y a que dichos resultados se publicaran (con alguna excepción que tuvo el efecto contrario al pretendido, puesto que la prohibición de publicar el famoso capítulo 5. ${ }^{\circ}$ del Informe FOESSA de 1970 tuvo una difusión clandestina muy superior a la que habría tenido de haber sido autorizado). Otra cosa habría sido si el 
IOP hubiese existido en soledad, con el monopolio de los estudios de opinión, pero no sólo no fue así, sino que el IOP fue la «punta de lanza» que abrió el camino a la liberalización de ese sector, de manera que la labor conjunta de todos ellos, IOP y empresas privadas, contribuyó mucho más de lo que sus protagonistas pensaron entonces al cambio político que se operó años más tarde, durante la transición. 